\title{
Granulocyte Colony-Stimulating Factor (Filgrastim) Treatment Primes for Increased ex Vivo Inducible Prostanoid Release
}

\author{
Sonja von Aulock, Eva-Maria Boneberg, Isabel Diterich, and Thomas Hartung \\ Biochemical Pharmacology, University of Konstanz, Konstanz, Germany \\ Received August 5, 2003; accepted November 7, 2003
}

\begin{abstract}
We investigated whether anti-inflammatory effects of treatment with granulocyte colony-stimulating factor (G-CSF, filgrastim) are mediated via prostaglandin $\mathrm{E}_{2}\left(\mathrm{PGE}_{2}\right)$ induction. In a double-blind crossover study, 10 healthy volunteers received 300 $\mu \mathrm{g}$ of filgrastim or saline 1 week apart. This was repeated after oral administration of $50 \mathrm{mg}$ of flurbiprofen $1 \mathrm{~h}$ before injection. The increase in neutrophilic granulocytes initiated by G-CSF was augmented significantly by flurbiprofen. Lipopolysaccharide-induced $P G E_{2}$ and thromboxane $\left(T \times B_{2}\right)$ release were increased $8 \mathrm{~h}$ after $\mathrm{G}-\mathrm{CSF}$ treatment. This increase was abro-
\end{abstract}

gated by flurbiprofen. However, flurbiprofen did not affect G-CSF-mediated decrease in tumor necrosis factor- $\alpha$ or interferon- $\gamma$ release. Of the volunteers treated with G-CSF, eight reported side effects (headache and bone pain) against none in the saline group. When flurbiprofen was given before injection, one volunteer each reported side effects in the G-CSF and in the saline group. These data show that G-CSF primes for increased $\mathrm{PGE}_{2}$ and $\mathrm{TxB}_{2}$ release. Cyclooxygenase inhibition counteracts neither the hematopoietic nor the anti-inflammatory activity of G-CSF but reduces side effects.

The granulocyte colony-stimulating factor (G-CSF) has been available in recombinant form as filgrastim (Neupogen) or lenograstim (Granocyte) for over a decade. It is used in the clinic to restore neutrophil counts and prime neutrophil functions to protect vulnerable patients from infection. G-CSF is approved for treatment of patients undergoing chemotherapy or also patients with acute neutropenia due to HIV (human immunodeficiency virus) infection.

Apart from increasing the production of neutrophilic granulocytes, continuous G-CSF administration also increases monocyte and lymphocyte production (Hartung et al., 1999; von Aulock et al., 2000). Also, G-CSF has anti-inflammatory effects on monocytes, increasing the release of cytokine antagonists, i.e., IL-1 receptor antagonist and the soluble TNF receptors; reducing the proinflammatory cytokine response, i.e., TNF $\alpha$, IL-1 $\beta$, IL-12, and consequently the lymphokine IFN $\gamma$; and increasing the release of IL- 6 and IL-8, in response to immune stimuli ex vivo (Hartung et al., 1995, 1999; Boneberg et al., 2000). These effects may be beneficial for immunoreconstitution of patients with HIV after initiation of highly active antiretroviral therapy (von Aulock and Har-

This study was supported by the German Research Council Grant 324/1 TP2.

Article, publication date, and citation information can be found at http://jpet.aspetjournals.org.

DOI: $10.1124 /$ jpet.103.058198. tung, 2002). In vitro, G-CSF decreases LPS-stimulated transcription of TNF $\alpha$, but IL- $1 \beta$ release is modulated on the level of pro-IL-1 $\beta$ processing (Boneberg et al., 2000; Boneberg and Hartung, 2002).

The side effects most commonly reported under G-CSF treatment are headache and mild bone pain, symptoms resembling the onset of a cold. However, the mechanism responsible for these side effects has not been investigated. Because prostaglandin ( $\mathrm{PG}) \mathrm{E}_{2}$ is considered the main mediator of pain, but also reduces the production of TNF $\alpha$ on the transcriptional level (Spatafora et al., 1991), we considered it a likely candidate to mediate the anti-inflammatory effects as well as the side effects of G-CSF.

Measurement of eicosanoid release by blood in response to stimulation has mainly been used to establish selectivity of NSAIDs (Glaser et al., 1995; Brideau et al., 1996; Riendeau et al., 2001; Blain et al., 2002). Eicosanoids regulate vasoand bronchotonus, induce pain and fever, and have immunosuppressive or chemotactic properties. Arachidonic acid released from the cells' membrane in response to stimulation is converted to $\mathrm{PGH}_{2}$ by constitutive cyclooxygenase- 1 and inducible cyclooxygenase-2 (COX, prostaglandin-endoperoxide synthase). $\mathrm{PGH}_{2}$ is then further metabolized by other enzymes to prostaglandins, prostacyclin, and thromboxanes. We have standardized a method to measure eicosanoid release in supernatants from in vitro-stimulated whole blood

ABBREVIATIONS: G-CSF, granulocyte colony-stimulating factor; IL, interleukin; TNF $\alpha$, tumor necrosis factor- $\alpha$; IFN $\gamma$, interferon- $\gamma$; LPS, lipopolysaccharide; PG, prostaglandin; NSAID, nonsteroidal anti-inflammatory drug; COX, cyclooxygenase; $T_{x B}$, thromboxane $B_{2} ; L^{2} B_{4}$, leukotriene $B_{4} ;$ U46.619, 9,11-dideoxy-11 $\alpha, 9 \alpha$-epoxymethanoprostaglandin F2 $\alpha$. 
incubations (von Aulock et al., 2003), which can also be used in the clinic to investigate the role of eicosanoid release in the course of diseases and to clarify correlations between cytokines and eicosanoids measured in the same samples. This report also describes the induction of eicosanoids by numerous other immune stimuli. For the present study, the well established stimulus LPS at a high concentration was chosen as a standard to assess eicosanoid release capacity.

Here, we investigate the effects of G-CSF treatment on eicosanoid release capacity and whether these eicosanoids play a role in the modulation of cytokine release by G-CSF by combining COX inhibition and G-CSF treatment.

\section{Materials and Methods}

Volunteer Population. The study protocol was reviewed and approved by the institutional review board of the University of Konstanz. All subjects gave written informed consent before study entry. Ten healthy Caucasian male volunteers, aged 22 to 32 years ( $28 \pm 1$ years) and weighing $77 \pm 2 \mathrm{~kg}$, were enrolled. The volunteers were free from signs or symptoms of acute infectious disease and had no history of clinically significant disease and took no medication for 4 weeks before the study.

Study Design. The protocol was double-blind and placebo-controlled for G-CSF treatment but unblinded for flurbiprofen treatment. Ten healthy male volunteers were randomized to two treatment groups, which were crossed over for G-CSF treatment. There was 1-week washout in between each of the four treatments. Clinical grade isotonic saline or $300 \mu \mathrm{g}$ of clinical grade, pyrogen-free filgrastim (Neupogen; Amgen, Munich, Germany) was administered s.c. at 9:00 AM in week 1 and crossed over in week 2 . This was repeated in weeks 3 and 4 and additionally every volunteer was given one 50-mg tablet of flurbiprofen (Froben; BASF Pharma, Abbott, Switzerland) at 8:00 AM., i.e., $1 \mathrm{~h}$ before the injection (Table 1).

Blood samples were collected immediately before treatment at 8:00 AM, 9:00 AM, and 5:00 PM on every day of treatment and at 9:00 AM on the following day. The volunteers had the right to withdraw from the study drug and study at any time for any reason. Volunteers would have been removed from the study in case of significant protocol violation, unacceptable side effects, or unrelated medical illness. No one withdrew from the study or was removed.

Differential Blood Counts. Differential blood counts were routinely performed on the blood of all volunteers to rule out acute infections and to control for changes in leukocyte subpopulations with a Pentra60 (ABX Diagnostics, Montpellier, France).

Whole Blood Incubations. Stimuli, i.e., LPS from Salmonella abortus equi or staphylococcal enterotoxin B (Sigma Chemie, Deisenhofen, Germany) or solvent, were added to $1600 \mu \mathrm{l}$ of RPMI 1640 medium; BioWhittaker, Verviers, Belgium) supplemented with 100 $\mathrm{IU} / \mathrm{ml}$ penicillin, $100 \mu \mathrm{g} / \mathrm{ml}$ streptomycin, and $2.5 \mathrm{IU} / \mathrm{ml}$ heparin (Liquemin; F. Hoffmann LaRoche, Grenzach-Whylen, Germany) and $400 \mu \mathrm{l}$ of heparinized whole blood in 2-ml polypropylene tubes (Eppendorf, Hamburg, Germany). In some experiments, 1 to $100 \mathrm{ng} / \mathrm{ml}$ rhG-CSF (Neupogen), $33 \mathrm{ng} / \mathrm{ml}$ to $1 \mu \mathrm{g} / \mathrm{ml} \mathrm{LTB}_{4}$ (Sigma Chemie), 33 $\mathrm{nM}$ to $1 \mu \mathrm{M}$ of the stable thromboxane receptor agonist $\mathrm{U} 46.619$ (Paesel, Frankfurt, Germany), or 0.02 to $10 \mu \mathrm{g} / \mathrm{ml} \mathrm{PGE}_{2}$ (Upjohn,
Heppenheim, Germany) was added to the incubations as well. After incubation at $37^{\circ} \mathrm{C}$ and $5 \% \mathrm{CO}_{2}$ for $24 \mathrm{~h}$, cells were sedimented by centrifugation and supernatants were frozen in aliquots at $-80^{\circ} \mathrm{C}$ until mediator measurement.

Mediator Measurements. Enzyme-linked immunosorbent assay was based on antibody pairs against TNF $\alpha$, IL- $1 \beta$, and IFN $\gamma$ (Endogen, Biozol, Eching, Germany), and IL-6 (R\&D, Wiesbaden, Germany). Binding of biotinylated antibody was quantified using streptavidin-peroxidase (Biosource, Camarillo, CA) and the substrate 3,3',5,5'-tetramethylbenzidine (Sigma Chemie). Recombinant cytokines serving as standards were gifts from Dr. S. Poole (National Institute for Biological Standards and Controls, Potters Bar, UK) (TNF $\alpha$, IL-1 $\beta$ ) or from Genzyme (Ruesselsheim, Germany) (IL-6), and Thomae (Biberach, Germany) (hu IFN $\gamma$ ). The enzyme immunoassays for $\mathrm{PGE}_{2}$ and $\mathrm{TxB}_{2}$ were purchased from Cayman (SPI Europe, Gif sur Yvette Cedex, France). All assays were performed according to manufacturers' instructions.

Statistics. Normal distribution of data were established in log transformed data. Repeated measures one-way analysis of variance was performed followed by Bonferroni's multiple comparison test (options of the GraphPad InStat 3.00; GraphPad Software Inc., San Diego, CA). $p<0.05$ was considered significant. Data are means \pm S.E.M. of the number of blood donors indicated calculated per milliliter of blood, i.e., corrected for the dilution factor of 5 .

\section{Results}

We investigated whether G-CSF affects LPS-induced eicosanoid formation directly in vitro. Addition of $100 \mathrm{ng} / \mathrm{ml}$ G-CSF to $10 \mu \mathrm{g} / \mathrm{ml}$ LPS did not influence $\mathrm{PGE}_{2}$ release, although TNF $\alpha$ release was significantly attenuated (Fig. 1). Preincubation of whole blood with G-CSF for up to $4 \mathrm{~h}$ yielded similar results. The release of $\mathrm{LTB}_{4}$ was also not influenced by addition of G-CSF (data not shown).

We verified that the addition of $\mathrm{PGE}_{2}$ to LPS-stimulated blood abrogates TNF $\alpha$ release (LPS plus solvent: $9 \pm 4 \mathrm{ng} / \mathrm{ml}$ versus LPS plus $20 \mathrm{ng} / \mathrm{ml} \mathrm{PGE}_{2}: 0.3 \pm 0.3 \mathrm{ng} / \mathrm{ml}$ blood, $p<$ 0.05). Similarly, LPS-induced IFN $\gamma$ release was suppressed in the presence of $\mathrm{PGE}_{2}$ (LPS plus solvent $66 \pm 26 \mathrm{ng} / \mathrm{ml}$ versus LPS plus $20 \mathrm{ng} / \mathrm{ml} \mathrm{PGE} 2: 3 \pm 2 \mathrm{ng} / \mathrm{ml}$ blood, $p<0.01$ ), whereas there was no significant effect on either other cytokine measured, i.e., IL- $1 \beta$ (LPS $18 \pm 8 \mathrm{ng} / \mathrm{ml}$ versus LPS plus $\mathrm{PGE}_{2} 17 \pm 6 \mathrm{ng} / \mathrm{ml}$ ) or IL-6 (LPS $3.4 \pm 0.6 \mathrm{ng} / \mathrm{ml}$ versus LPS plus $\mathrm{PGE}_{2} 3.0 \pm 0.8 \mathrm{ng} / \mathrm{ml}$ ). However, stimulation of whole blood with LPS in the presence of $\mathrm{LTB}_{4}$ (up to $1 \mu \mathrm{g} / \mathrm{ml}$ ) or the stable thromboxane agonist U46.619 (up to $1 \mu \mathrm{g} / \mathrm{ml}$ ) had no significant effect on LPS-inducible TNF $\alpha$, IL-1 $\beta$, IL-6, or IFN $\gamma$ (data not shown). Thus, although G-CSF in vitro did not affect eicosanoid release, we showed effects of $\mathrm{PGE}_{2}$ similar to those of G-CSF, implicating it as a potential mediator of the attenuated TNF $\alpha$ and IFN $\gamma$ production observed under G-CSF treatment.

To determine whether G-CSF treatment induces endogenous $\mathrm{PGE}_{2}$ formation directly, serum levels were measured

TABLE 1

Study design of the volunteer study

\begin{tabular}{|c|c|c|c|c|}
\hline Group & Week 1 & Week 2 & Week 3 & Week 4 \\
\hline $\begin{array}{l}1(n=5) \\
2(n=5)\end{array}$ & $\begin{array}{l}\text { Placebo }^{a} \\
\text { Filgrastim }^{b}\end{array}$ & $\begin{array}{l}\text { Filgrastim } \\
\text { Placebo }\end{array}$ & $\begin{array}{l}\text { Flurbiprofen } \\
\text { Placebo } \\
\text { Flurbiprofen } \\
\text { Filgrastim }\end{array}$ & $\begin{array}{l}\text { Flurbiprofen } \\
\text { Filgrastim } \\
\text { Flurbiprofen } \\
\text { Placebo }\end{array}$ \\
\hline
\end{tabular}

\footnotetext{
a Isotonic saline.

${ }^{b} 300 \mu \mathrm{g}$ of filgrastim s.c.

${ }^{c} 50 \mathrm{mg}$ of flurbiprofen p.o.
} 


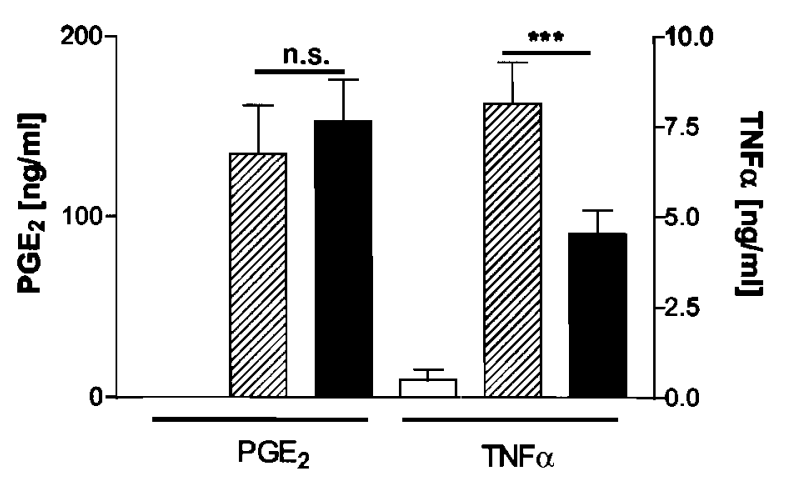

Fig. 1. G-CSF does not modulate LPS-induced $\mathrm{PGE}_{2}$ release in vitro. Whole blood (20\%) from 10 donors was stimulated with $10 \mu \mathrm{g} / \mathrm{ml}$ LPS (hatched bars) or $10 \mu \mathrm{g} / \mathrm{ml}$ LPS plus $100 \mathrm{ng} / \mathrm{ml}$ G-CSF (black bars) overnight. $\mathrm{PGE}_{2}$ and $\mathrm{TNF} \alpha$ were measured in the supernatant. Data are means \pm S.E.M.; n.s., not significant; $* * *, p<0.001$.

before and up to $24 \mathrm{~h}$ after treatment with $480 \mu \mathrm{g}$ of G-CSF $(n=6)$ or placebo $(n=4)$ in samples from a study reported previously (Boneberg et al., 2000). Serum $\mathrm{PGE}_{2}$ did not differ significantly between the placebo or G-CSF treatment groups either before treatment or 2, 4, 8, or $24 \mathrm{~h}$ after injection (Fig. 2 ; mean values in serum without treatment were $227 \pm 17$ $\mathrm{pg} / \mathrm{ml}$ ). Therefore, both in vitro and in vivo results concur, indicating that G-CSF treatment does not induce physiologically relevant endogenous systemic $\mathrm{PGE}_{2}$ release.

However, when 10 volunteers were injected with $300 \mu \mathrm{g}$ of G-CSF, ex vivo LPS-inducible $\mathrm{PGE}_{2}$ and $\mathrm{TxB}_{2}$ levels in whole blood incubations were increased about 3 - and 2 -fold, respectively, above levels induced in blood from placebo-treated volunteers $8 \mathrm{~h}$ after treatment. Twenty-four hours after treatment, inducible prostanoid levels were again similar in both groups (Fig. 3a). In the same samples, LPS-inducible $\mathrm{TNF} \alpha$ release calculated per monocyte was halved in blood from G-CSF-treated volunteers, whereas IFN $\gamma$ release was reduced to one-third of placebo values (Fig. 3b). Incidentally, although LPS-inducible TNF $\alpha$ release did not vary significantly over the course of a day, IFN $\gamma$ release was consistently greater in blood drawn in the afternoon compared with blood drawn in the morning.

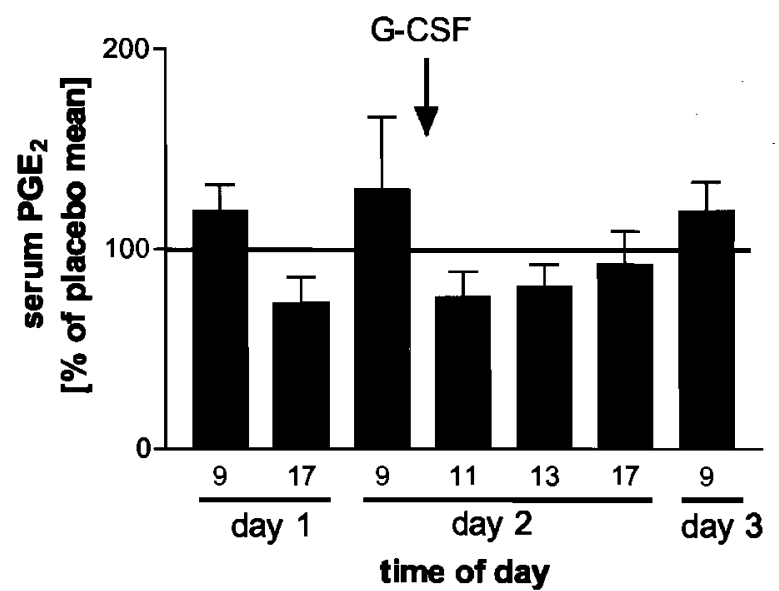

Fig. 2. G-CSF administration does not alter the levels of serum $\mathrm{PGE}_{2}$ Serum levels of $\mathrm{PGE}_{2}$ were measured in healthy volunteers treated with $480 \mu \mathrm{g}$ of G-CSF (filgrastim) $(n=6)$ or placebo $(n=4)$ at the time points indicated. The study design was reported earlier (Boneberg et al., 2000). Data are normalized to placebo (set to $100 \%$ for each time point) \pm S.E.M. There were no significant differences between the two groups at any time point.
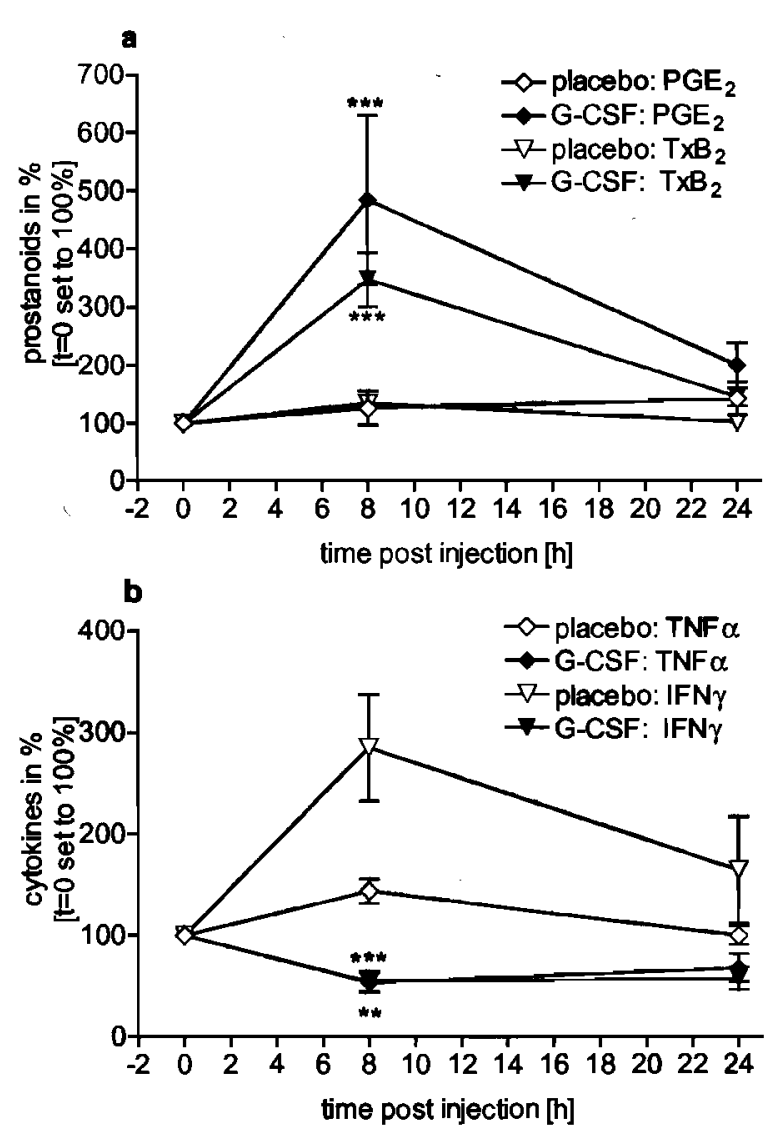

Fig. 3. G-CSF treatment modulates LPS-induced prostanoid and cytokine release. Prostanoid $\left(\mathrm{TxB}_{2}\right.$ and $\mathrm{PGE}_{2}$ ) and cytokine (TNF $\alpha$ and IFN $\gamma$ calculated per $10^{6}$ monocytes or lymphocytes, respectively) release in response to $10 \mu \mathrm{g} / \mathrm{ml}$ LPS from $S$. abortus equi. Times are given relative to injection of $300 \mu \mathrm{g}$ of G-CSF (filgrastim) or placebo. Initial values are set to $100 \%$, values are means \pm S.E.M.; $* *, p<0.01 ; * * *, p<0.001$.

In the second half of the treatment study, one 50-mg tablet of flurbiprofen was given $1 \mathrm{~h}$ before G-CSF or placebo injection. Blood samples were taken immediately before administration of flurbiprofen and immediately before administration of G-CSF or placebo $1 \mathrm{~h}$ later and $8 \mathrm{~h}$ after injection of G-CSF or placebo, i.e., $9 \mathrm{~h}$ after administration of flurbiprofen. Figure 4 confirms that flurbiprofen is very effective in reducing LPS-induced $\mathrm{PGE}_{2}$ and $\mathrm{TxB}_{2}$ release within $1 \mathrm{~h}$ of ingestion. The observation that the values before any treatment $(t=-1 \mathrm{~h})$ in the group receiving flurbiprofen and placebo were higher than in the other groups is a result of day-to-day variation. This stresses further the strength of the effect, i.e., the difference is even greater when the prostanoid values induced before treatment $(t=-1 \mathrm{~h})$ are compared with those $1 \mathrm{~h}$ after ingestion $(t=0 \mathrm{~h})$ in that group. This effect was still in place $9 \mathrm{~h}$ after ingestion of the tablet, i.e., $8 \mathrm{~h}$ after placebo or G-CSF injection. Twenty-four hours after ingestion of flurbiprofen, LPS-inducible $\mathrm{PGE}_{2}$ levels were still decreased compared with starting values, although $\mathrm{TxB}_{2}$ levels had returned to pretreatment values.

Although prostanoid release was attenuated when flurbiprofen was given before G-CSF injection, TNF $\alpha$ release per monocyte and IFN $\gamma$ release per lymphocyte remained significantly below placebo values at levels equal to values attained under G-CSF treatment without prior flurbiprofen treatment (Fig. 5) even though initial LPS-inducible IFN $\gamma$ release at $t=-1 \mathrm{~h}$ and $t=0 \mathrm{~h}$ was significantly greater in 

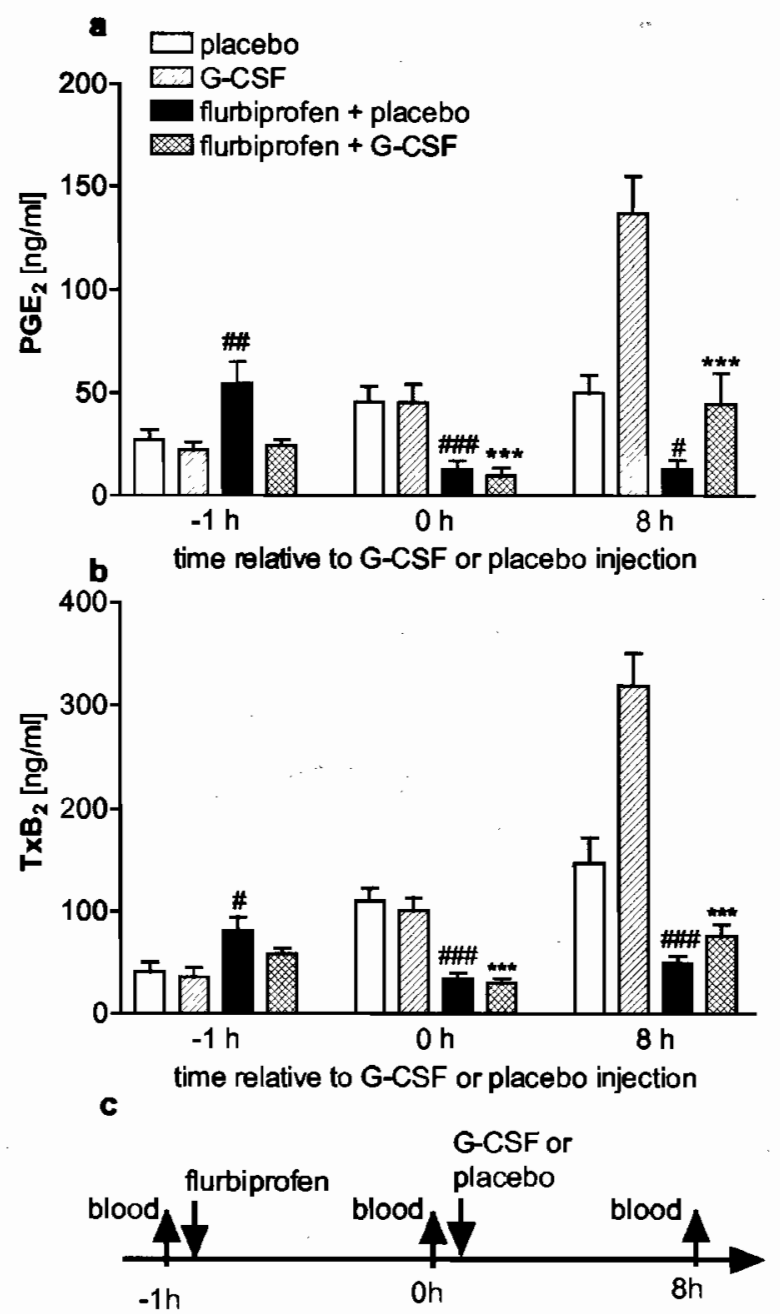

Fig. 4. Flurbiprofen treatment prevents G-CSF-dependent priming for prostanoid release. $\mathrm{PGE}_{2}(\mathrm{a})$ and $\mathrm{TxB}_{2}$ (b) release in response to $10 \mu \mathrm{g} / \mathrm{ml}$ LPS from $S$. abortus equi. c, treatment scheme. Values are means \pm S.E.M.; \#, $p<0.05 ; \# \#, p<0.01 ; \# \# \#, p<0.001$ relative to placebo without flurbiprofen; ***, $p<0.001$ relative to G-CSF without flurbiprofen.

the group receiving flurbiprofen and G-CSF compared with the other groups.

Interestingly, the combination of flurbiprofen with G-CSF treatment did not counteract G-CSF-induced leukocytosis, but instead actually added significantly to the effect. The differential blood cell counts revealed that flurbiprofen had further increased the recruitment of neutrophilic granulocytes, indicating that the prostanoids play a role in controlling neutrophil production negatively (Fig. 6). A carryover effect from the first G-CSF treatment on the leukocyte counts was excluded by the differential blood cell count. However, it cannot be ruled out that the greater efficacy of the second G-CSF injection 2 weeks after the first treatment could be due to a larger marrow pool of neutrophils. On the other hand, we have no indications for such effects from a previous study in which volunteers received G-CSF treatment on a weekly basis (von Aulock et al., 2000).

Volunteers were asked about side effects on the day after every treatment. Eight of 10 volunteers reported headache or bone pain after G-CSF treatment against zero complaints from the placebo-treated volunteers. However, when volunteers received flurbiprofen before G-CSF injection, one vol-

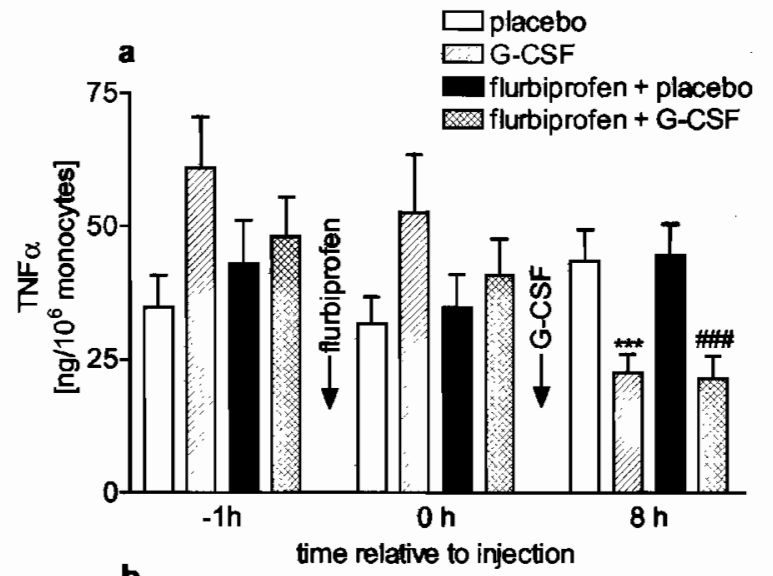

b

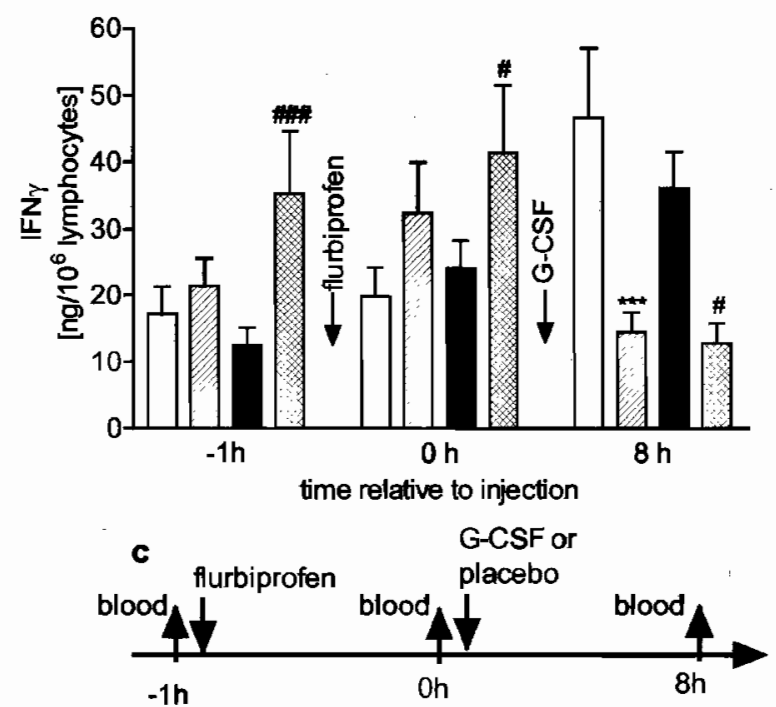

Fig. 5. Flurbiprofen treatment does not affect modulation of cytokine release by G-CSF treatment. $\mathrm{TNF}_{\alpha}$ (a) and $\mathrm{IFN} \gamma(\mathrm{b})$ release in response to $10 \mu \mathrm{g} / \mathrm{ml}$ LPS from $S$. abortus equi. c, treatment scheme. Values are means \pm S.E.M.; \#, $p<0.05$; \#\#\#, $p<0.001$ relative to placebo without flurbiprofen; $* * *, p<0.001$ relative to G-CSF without flurbiprofen.

unteer reported side effects in both the placebo and the G-CSF-treated group. It seems that the side effects commonly associated with G-CSF treatment are mediated by eicosanoids and can be prevented effectively by cyclooxygenase inhibition without interfering negatively with neutrophil recruitment or with the anti-inflammatory effects of G-CSF treatment.

\section{Discussion}

The results presented in this article demonstrate that there is a significant discrepancy between the effects of GCSF in vitro in comparison to ex vivo with regard to the modulation of prostanoid release. Incubation of whole blood with G-CSF in vitro decreases LPS-stimulated release of $\mathrm{TNF} \alpha$ or IFN $\gamma$ as can also be seen in blood from G-CSFtreated volunteers even $24 \mathrm{~h}$ after treatment. However, whole blood preincubated with G-CSF in vitro was not able to bring about the priming for eicosanoid release that could be observed in ex vivo-stimulated blood from G-CSF-treated volunteers. Apparently, the cells recruited by G-CSF from the bone marrow differ in their characteristics compared with the more mature population found in the blood of un- 


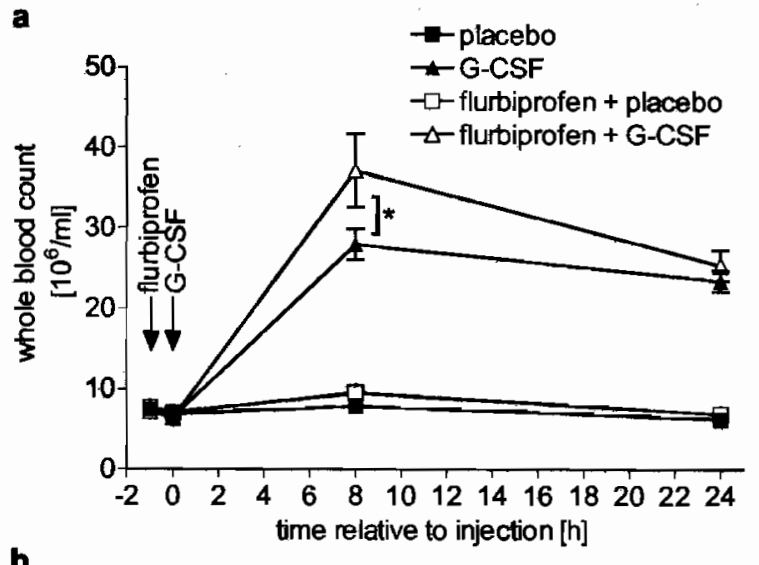

b

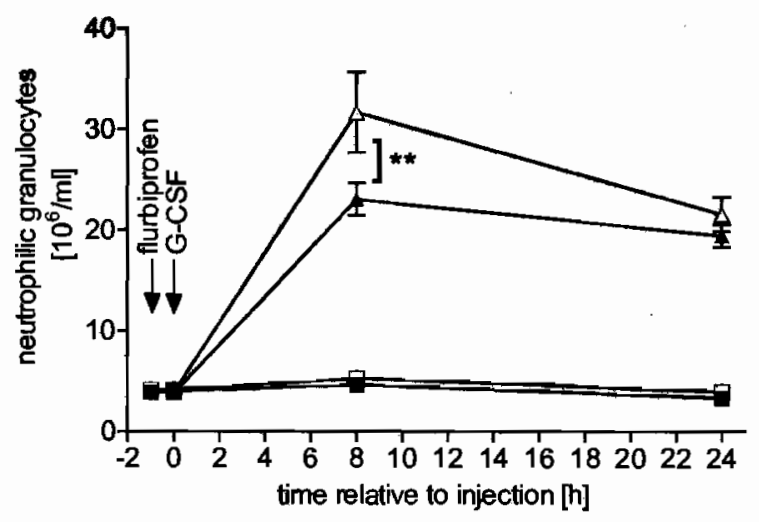

C

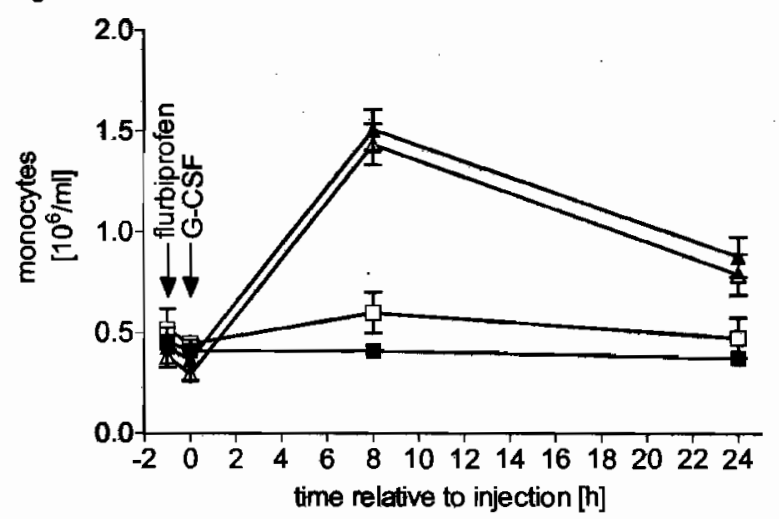

Fig. 6. Flurbiprofen treatment augments G-CSF-induced granulopoiesis Whole blood cell count (a), differential neutrophilic granulocyte count (b) and monocyte count (c) in blood from volunteers. One 50-mg tablet of flurbiprofen was administered at $\mathrm{t}=-1 \mathrm{~h}$ and $300 \mu \mathrm{g}$ of G-CSF (filgrastim) or placebo was injected at $t=0 \mathrm{~h}$ as indicated. All combinations of placebo versus G-CSF at 8 and $24 \mathrm{~h}$ were highly significantly differen $(p<0.001)$. Values are means \pm S.E.M.; $*, p<0.05 ; * *, p<0.01$ relative to G-CSF without flurbiprofen.

treated donors. It seems unlikely that the increased prostanoid levels induced in blood from G-CSF-treated volunteers on stimulation merely reflect increased populations of the producing cells, because the priming can only be observed $8 \mathrm{~h}$ after G-CSF treatment and baseline values are achieved $24 \mathrm{~h}$ after treatment, whereas the cell counts still significantly increased during this time period. This observation poignantly illustrates that not all effects of G-CSF can be modeled in vitro. Although the ex vivo effects of G-CSF on TNF formation could also be modeled in vitro, this did not translate to its effects on eicosanoids. This suggests that G-CSF treatment recruits a different population of peripheral leukocytes.

The lack of effect of G-CSF on the serum levels of $\mathrm{PGE}_{2}$ suggests that the nature of the effect of G-CSF treatment is limited to priming for increased response to inflammatory stimuli, and not to direct activation of cells. Even at a higher dose than given in the main study, there was no effect on $\mathrm{PGE}_{2}$ levels; in fact, the tendency toward lower $\mathrm{PGE}_{2}$ levels compared with the placebo group and to the values before G-CSF treatment does not give rise to expectations that this would be different with even lower doses of G-CSF.

It is not clear which cells in the blood are the main producers of prostanoids. $\mathrm{TxB}_{2}$ and $\mathrm{PGE}_{2}$ can be released by both monocytes and neutrophils (Nichols et al., 1987; Doerfler et al., 1989; Nusing et al., 1990; Zheng et al., 1990; Juergens et al., 1992; Saareks et al., 1993; Patrignani et al., 1994; Aibiki and Cook, 1997), although this was not found for both populations by all investigators. Furthermore, platelets, which were also present in the whole blood incubations, express the highest amounts of thromboxane synthase (Nusing et al., 1990) and can release $\mathrm{TxB}_{2}$, not only in response to coagulation, which was prevented here with heparin, but also in response to inflammatory stimulation (Saareks et al, 1993; Reale et al., 1996). In contrast, intracellular cytokine staining of LPS-stimulated whole blood showed that TNF $\alpha$ is produced exclusively by monocytes (Boneberg and Hartung, 2002 ) in this experimental setup. Similarly, IFN $\gamma$ is clearly produced only by lymphocytes (Okamura et al., 1998; Boneberg et al., 2000), allowing a relation of the release of these cytokines to the producing cell numbers and accounting for the changes in differential blood cell counts due to the treatment.

$\mathrm{PGE}_{2}$ was able to inhibit LPS-induced TNF $\alpha$ as well as IFN $\gamma$ release in vitro, making it a candidate mediator of the anti-inflammatory effects of G-CSF in vivo. The strong increase in LPS-induced $\mathrm{PGE}_{2}$ and $\mathrm{TxB}_{2}$ induction under GCSF treatment was already realized $8 \mathrm{~h}$ after treatment. However, effective inhibition of prostanoid production by additional administration of flurbiprofen did not restore LPSinduced proinflammatory cytokine release. The similarity in the effects of $\mathrm{PGE}_{2}$ and $\mathrm{G}-\mathrm{CSF}$ in reducing the release of TNF $\alpha$ and IFN $\gamma$ prompted the hypothesis of an induction of PGE $_{2}$ by G-CSF. However, the anti-inflammatory effects of G-CSF were not attenuated by NSAID in vitro (Fig. 1) or ex vivo (Fig. 4). These results prove the hypothesis, that the anti-inflammatory effects of G-CSF require prostanoid mediation, false. Instead, the reduction in the release of proinflammatory cytokines seems to be a direct effect of G-CSF on monocytes, which carry a functional G-CSF receptor (Boneberg et al., 2000).

Although flurbiprofen administration alone had no significant effects on the whole blood cell count, it significantly augmented the hematopoietic effects of G-CSF by recruiting additional neutrophils. This observation substantiates previous observations in rodent cells attributing a granulocyte colony-inhibitory activity to $\mathrm{PGE}_{2}$ (Gentile and Pelus, 1988; Santangelo et al., 2000). A mechanism explaining this observation has not yet been put forward; a likely explanation is that the endogenously formed prostanoid regulates hematopoiesis negatively.

It also remains to be tested whether the combination of G-CSF with NSAIDs could further increase granulopoiesis in 
leukopenic patients. Pain management is commonly part of the treatment of these patients; therefore, this question might be answered by a retrospective analysis of clinical data.

It seems that $\mathrm{PGE}_{2}$ may antagonize the granulopoietic effects of G-CSF to prevent excessive neutrophil recruitment. Although we found no difference in the $\mathrm{PGE}_{2}$ serum levels of G-CSF-treated volunteers after G-CSF administration, the time points were possibly chosen too early and too late because the reported side effects usually occurred within 8 to $16 \mathrm{~h}$ of administration. However, serum samples from a former G-CSF treatment study with higher resolution also showed no elevation of serum $\mathrm{PGE}_{2}$. On the other hand, $\mathrm{PGE}_{2}$ release in vivo might not be systemic and might only work locally within the bone marrow.

However, the type of side effects reported, i.e., headache and bone pain, which are consistently reported under G-CSF treatment, do support the hypothesis that $\mathrm{PGE}_{2}$ may be induced directly in vivo by high concentrations of G-CSF as a negative feedback. The effectiveness of prior flurbiprofen administration in preventing the side effects associated with G-CSF administration further supports this concept.

Together, these data show that G-CSF primes for increased $\mathrm{PGE}_{2}$ and $\mathrm{TxB}_{2}$ release ex vivo. Cyclooxygenase inhibition counteracts neither the hematopoietic nor the antiinflammatory activity of G-CSF but prevents associated side effects.

\section{Acknowledgments}

We thank Stefan Fennrich, Corinna Hermann, Pascal Renner, Susanne Deininger, and Lars Hareng for prompt help.

\section{References}

Aibiki M and Cook JA (1997) Ulinastatin, a human trypsin inhibitor, inhibits endotoxin-induced thromboxane B2 production in human monocytes. Crit Care Med 25:430-434.

Blain H, Boileau C, Lapicque F, Nedelec E, Loeuille D, Guillaume C, Gaucher A, Jeandel C, Netter P, and Jouzeau JY (2002) Limitation of the in vitro whole blood assay for predicting the COX selectivity of NSAIDs in clinical use. $\mathrm{Br} J \mathrm{Clin}$ Pharmacol 53:255-265.

Boneberg EM, Hareng L, Gantner F, Wendel A, and Hartung T (2000) Human monocytes express functional receptors for granulocyte colony-stimulating factor that mediate suppression of monokines and interferon-gamma. Blood 95:270-276.

Boneberg EM and Hartung T (2002) Granulocyte colony-stimulating factor attenuates LPS-stimulated IL-1beta release via suppressed processing of proIL-1beta, whereas TNF-alpha release is inhibited on the level of proTNF-alpha formation. Eur J Immunol 32:1717-1725.

Brideau C, Kargman S, Liu S, Dallob AL, Ehrich EW, Rodger IW, and Chan CC (1996) A human whole blood assay for clinical evaluation of biochemical efficacy of cyclooxygenase inhibitors. Inflamm Res 45:68-74

Doerfler ME, Danner RL, Shelhamer JH, and Parrillo JE (1989) Bacterial lipopoly- saccharides prime human neutrophils for enhanced production of leukotriene B4. $J$ Clin Investig 83:970-977.

Gentile PS and Pelus LM (1988) In vivo modulation of myelopoiesis by prostaglandin E2. IV. Prostaglandin E2 induction of myelopoietic inhibitory activity. J Immunol 141:2714-2720.

Glaser K, Sung ML, O’Neill K, Belfast M, Hartman D, Carlson R, Kreft A, Kubrak D,

Hsiao CL, and Weichman B (1995) Etodolac selectively inhibits human prostaglandin G/H synthase 2 (PGHS-2) versus human PGHS-1. Eur J Pharmacol 281:107-111.

Hartung T, Docke WD, Gantner F, Krieger G, Sauer A, Stevens P, Volk HD, and Wendel A (1995) Effect of granulocyte colony-stimulating factor treatment on ex vivo blood cytokine response in human volunteers. Blood 85:2482-2489.

Hartung T, Doecke WD, Bundschuh D, Foote MA, Gantner F, Hermann C. Lenz A, Milwee S, Rich B, Simon B, et al. (1999) Effect of filgrastim treatment on inflammatory cytokines and lymphocyte functions. Clin Pharmacol Ther 66:415-424.

Juergens UR, Christiansen SC, Stevenson DD, and Zuraw BL (1992) Arachidonic acid metabolism in monocytes of aspirin-sensitive asthmatic patients before and after oral aspirin challenge. J Allergy Clin Immunol 90:636-645.

Nichols FC, Schenkein HA, and Rutherford RB (1987) Prostaglandin E2, prostaglandin $\mathrm{E} 1$ and thromboxane B2 release from human monocytes treated with $\mathrm{C} 3 \mathrm{~b}$ or bacterial lipopolysaccharide. Biochim Biophys Acta 927:149-157.

Nusing R, Lesch R, and Ullrich V (1990) Immunohistochemical localization of thromboxane synthase in human tissues. Eicosanoids 3:53-58.

Okamura H, Kashiwamura S, Tsutsui H, Yoshimoto T, and Nakanishi K (1998) Regulation of interferon-gamma production by IL-12 and IL-18. Curr Opin Immunol 10:259-264.

Patrignani P, Panara MR, Greco A, Fusco O, Natoli C, Tacobelli S, Cipollone F, Ganci A, Creminon C, Maclouf J, et al. (1994) Biochemical and pharmacological characterization of the cyclooxygenase activity of human blood prostaglandin endoperoxide synthases. J Pharmacol Exp Ther 271:1705-1712.

Reale M, Barbacane RC, Frydas S, Anogianakis G, Trakatellis A, Dimitriadou D, Vacalis D, Placido FC, De Fazio P, Porreca E, et al. (1996) Human recombinant interleukin-1 beta induces thromboxane A2 release in polymorphonuclear leukocytes, macrophages and platelets: effect of IL-1 receptor antagonist. Mol Cell Biochem 159:163-168.

Riendeau D, Percival MD, Brideau C, Charleson S, Dube D, Ethier D, Falgueyret JP, Friesen RW, Gordon R, Greig G, et al. (2001) Etoricoxib (MK-0663): preclinical profile and comparison with other agents that selectively inhibit cyclooxygenase-2. $J$ Pharmacol Exp Ther 296:558-566.

Saareks V, Riutta A, Mucha I, Alanko J, and Vapaatalo H (1993) Nicotine and cotinine modulate eicosanoid production in human leukocytes and platelet rich plasma. Eur $J$ Pharmacol 248:345-349.

Santangelo S, Shoup M, Gamelli RL, and Shankar R (2000) Prostaglandin E2 receptor antagonist (SC-19220) treatment restores the balance to bone marrow myelopoiesis after burn sepsis. J Trauma 48:826-830; discussion, 830-821.

Spatafora M, Chiappara G, D'Amico D, Volpes D, Melis M, Pace E, and Merendino AM (1991) Prostaglandin E2 down-regulates the expression of tumor necrosis alpha gene by human blood monocytes. Adv Prostaglandin Thromboxane Leukot Res 21B:521-524.

von Aulock S, Boneberg EM, and Hartung T (2000) Intermittent G-CSF (filgrastim) treatment cannot induce lymphocytosis in volunteers. Clin Pharmacol Ther 68: 104

von Aulock S and Hartung T (2002) Potential for immune reconstitution through G-CSF treatment of HIV patients. Arch Immunol Ther Exp 50:111-120.

von Aulock S, Hermann C, and Hartung T (2003) Determination of the eicosanoid response to inflammatory stimuli in whole blood and its pharmacological modulation ex vivo. J Immunol Methods 277:53-63.

Zheng H, Crowley JJ, Chan JC, Hoffmann H, Hatherill JR, Ishizaka A, and Raffin TA (1990) Attenuation of tumor necrosis factor-induced endothelial cell cytotoxicity and neutrophil chemiluminescence. Am Rev Respir Dis 142:1073-1078.

Address correspondence to: Dr. Thomas Hartung, Biochemical Pharmacology, University of Konstanz, P.O. Box M655, 78457 Konstanz, Germany. E-mail: thomas.hartung@uni-konstanz.de 